\title{
The Dynamic Relationship Between End-Tidal Sevoflurane Concentrations, Bispectral Index, and Cerebral State Index in Children
}

Ricardo Fuentes, MD*

Luis I. Cortínez, MD*

Michel M. R. F. Struys, MD, PhD十‡

Alejandro Delfino, $\mathrm{MD}^{*}$

Hernán Muñoz, MD, MSc*
BACKGROUND: To guide anesthetic administration with electroencephalogram monitors in children, an adequate characterization of the anesthetic effect measured by these monitors in this population is needed. We sought to quantify and compare the dynamic profile of sevoflurane's effect measured with the cerebral state index (CSI) and the bispectral index (BIS) in children.

METHODS: Fifteen healthy children, aged 3-15 yr, scheduled to undergo minor surgery were prospectively studied. During the simultaneous recording of CSI and BIS, the sevoflurane vaporizer was set at $6 \mathrm{vol} \%$ for $5 \mathrm{~min}$ and then decreased. End-tidal concentrations $\left(C_{\mathrm{ET}}\right)$ were measured. The $C_{\mathrm{ET}}$-sevoflurane effect-site concentration equilibration and pharmacodynamics were modeled. Goodness of fit between models was compared. Data are typical value (coefficient of variation). RESULTS: Within the anesthetic depth range studied, the rate of change of sevoflurane's effect expressed as the effect-site equilibration half-life $\left(t_{1 / 2} k_{\mathrm{e} 0}\right)$ was slower with the CSI [2.0 (14) min] than with BIS [1.2 (53) $\mathrm{min}](P<0.05)$. The estimated baseline effect of BIS and CSI before sevoflurane administration $\left(E_{0}\right)$ was 84 (39) for CSI and 87 (7) for BIS (NS). The sensitivity to sevoflurane hypnotic effect expressed in the $C_{50}$ [steady-state $C_{\mathrm{ET}}$ eliciting half of the maximum response $\left(E_{\max }\right)$ ] was 2.1 (68) \% with CSI and $2.1(16) \%$ with BIS (NS). The $E_{\max }$ with CSI 45 (0) was higher than that with BIS $27(39)(P<0.05)$. The population prediction error was significantly better for BIS $(-0.7 \pm 26.9)$ than for CSI $(-3.0 \pm 178.6)(P<0.05)$. CONCLUSIONS: In children, the $t_{1 / 2} k_{\mathrm{e} 0}$ of sevoflurane and the pharmacodynamics of sevoflurane were quantified and the results were entirely dependent on the monitor used to measure its hypnotic effect. Within the anesthetic depth range studied, the rate of change of sevoflurane's effect was slower with the CSI. To adequately guide sevoflurane administration with these monitors in children, these differences should be considered.

(Anesth Analg 2008;107:1573-8) he bispectral index (BIS) monitor (Aspect Medical Systems, Newton, MA) and the cerebral state monitor (CSM Danmeter A/S, Odense, Denmark) are electroencephalogram (EEG) devices that have been used to guide anesthetic administration in children. ${ }^{1-4}$ Using their own algorithms, ${ }^{5,6}$ which were derived from adult EEG data, these monitors calculate indices that can range from 100 (fully awake) to 0 (isoelectric EEG).

Different EEG monitors have been shown to behave differently under similar anesthetic conditions. ${ }^{7,8}$ Therefore, an adequate characterization of the effect measured by each device is mandatory before using them

From the *Departamento de Anestesiología, Facultad de Medicina, Pontificia Universidad Católica de Chile, Santiago, Chile; tDepartment of Anesthesia, University Medical Center Groningen, Groningen, The Netherlands, and łDepartment of Anesthesia, Ghent University, Ghent, Belgium.

Accepted for publication May 16, 2008.

Address correspondence and reprint requests to Dr. Luis I. Cortínez, Departamento de Anestesiología, Hospital Clínico U. Católica, Marcoleta 367, Santiago, Chile. Address e-mail to licorti@ med.puc.cl.

Copyright (C) 2008 International Anesthesia Research Society DOl: 10.1213/ane.0b013e318181ef88 as tools to guide anesthetic administration. This effect can be studied during nonsteady-state conditions through the application of an effect compartment model. ${ }^{9}$ With this approach, it is possible to characterize both the effect-site concentration (Ce) versus effect relationship and the speed of onset and offset of the anesthetic action measured with these monitors.

Sevoflurane is the most frequently used inhaled anesthetic for induction of anesthesia in children. The aim of this study is to quantify and compare the dynamic profile of sevoflurane's effect measured with the cerebral state index (CSI) calculated by the CSM and BIS in children.

\section{METHODS}

After local ethics committee approval (Facultad de Medicina, Pontificia Universidad Católica, Santiago, Chile), informed written consent was obtained from the parents of all patients. Fifteen ASA I children, aged 3-15 yr, were prospectively studied from December 2006 to March 2007. All patients were scheduled to undergo elective surgery under general anesthesia 
and did not receive any premedication. Exclusion criteria were any known central nervous system disease, recent administration ( $48 \mathrm{~h}$ ) of any drug acting in the central nervous system, and any known adverse effect to the study drug.

In the operating room, standard monitoring was applied. At this time, the pediatric sensors of the Aspect A-2000 BIS ${ }^{\circledR}$ monitor (version XP) and the standard electrodes of the CSM model 2 monitor were placed on each patient according to the manufacturers' recommendations. The smoothing time period of the BIS monitor was set at $15 \mathrm{~s}$. BIS values were automatically recorded and transferred to computer hard disk for off-line analysis using the Hyperterminal (Microsoft, Redmond, VA) program. The CSM updates the CSI every $1 \mathrm{~s}$ and has a fixed smoothing time of around $10 \mathrm{~s} .{ }^{10}$ The CSI data were recorded using the Danmeter A/S CSM capture V2.02 onto the computer hard disk. The BIS and the CSI were recorded simultaneously during the study period.

The Datex Capnomac monitor (GE Healthcare, Helsinski, Finland) was used to measure sevoflurane end-tidal concentrations $\left(C_{\text {Etsevo }}\right)$. Measurements were automatically registered every $10 \mathrm{~s}$ throughout the study period and transferred to computer hard disk using the software program Hyperterminal (Microsoft).

Before sevoflurane administration, a 1-min baseline period was recorded. During this period, patients were kept undisturbed and spontaneously breathing through a facemask. During the transition period, fresh gas flow (100\% oxygen) was maintained at 5 $\mathrm{L} / \mathrm{min}$, the mask was manually sealed as tight as possible, and ventilation was assisted to maintain end-tidal carbon dioxide concentrations between 30 and $35 \mathrm{~mm} \mathrm{Hg}$. The sevoflurane vaporizer was turned to $6 \%$ for 5 min or until burst suppression (BS) $\geq 80 \%$. Immediately after, the vaporizer was turned-off until BIS returned to values $>60$. At this point, the study was finished and anesthesia continued according to the anesthesiologist's criteria.

Before starting the recording of CSI and BIS data, the time of both monitors was synchronized. Pairwise CSI and BIS data obtained every $5 \mathrm{~s}$ was used in the subsequent analysis. The baseline awake BIS and CSI values (mean $\pm \mathrm{SD}$ ) were calculated using data recorded before sevoflurane administration. The data were judged adequate for baseline calculations if the signal quality index of BIS and CSI was $>20 \%$ for $30 \mathrm{~s}$.

To study the relationship between sevoflurane concentrations in the effect compartment $\left(\mathrm{Ce}_{\text {sevo }}\right)$ and the corresponding BIS or CSI values, it was assumed that $C_{\text {ETsevo }}$ reflected its plasma concentration $(\mathrm{Cp})$ and that $\mathrm{Ce}_{\text {sevo }}$ was linearly linked to $\mathrm{Cp}$. $\mathrm{Ce}_{\text {sevo }}$ was estimated as:

$$
\frac{d \mathrm{Ce}}{d t}=K_{\mathrm{e} 0} \times\left(C_{\mathrm{ETsevo}}-\mathrm{Ce}_{\mathrm{sevo}}\right)
$$

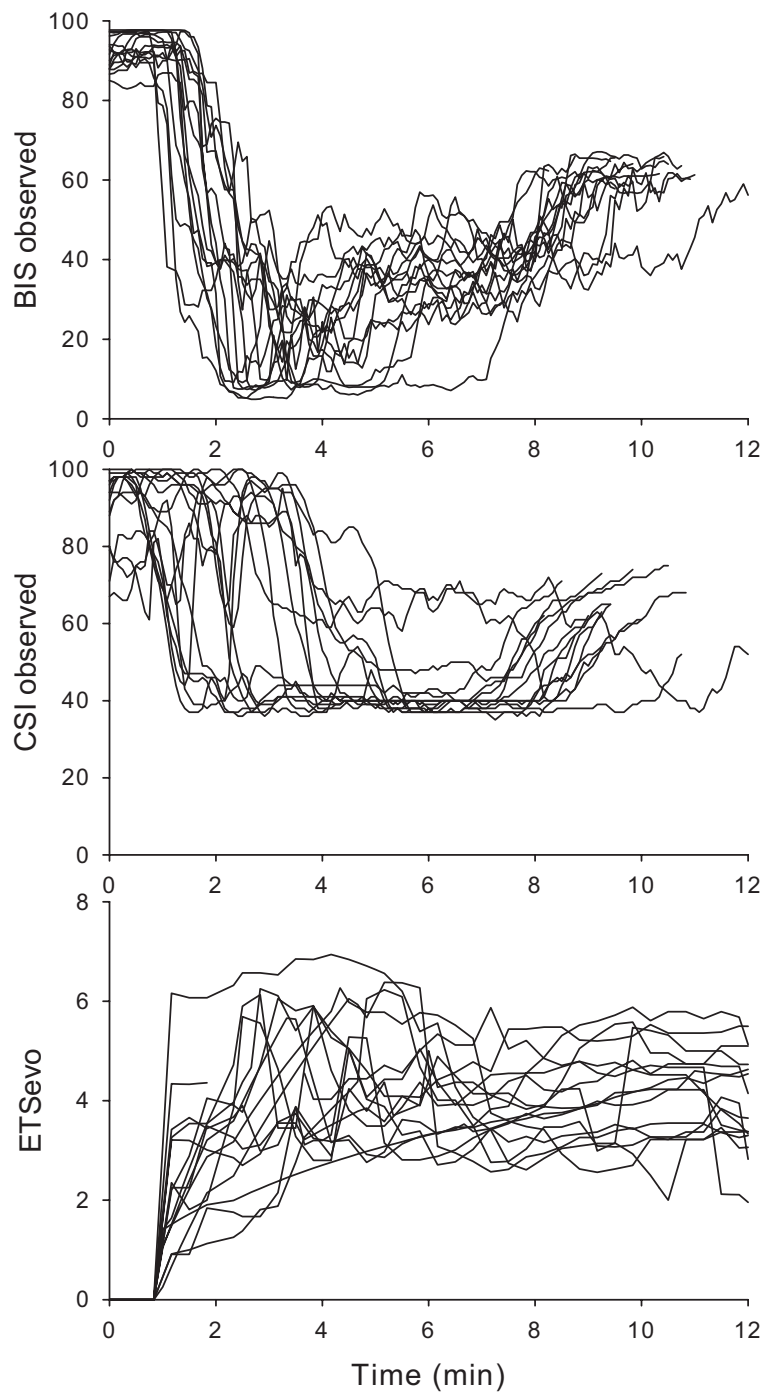

Figure 1. Time course of measured bispectral index (BIS), cerebral state index (CSI), and end-tidal sevoflurane concentrations for each patient.

where the $k_{\mathrm{e} 0}$ is the first-order $C_{\mathrm{ETsevo}}$ versus $\mathrm{Ce}_{\text {sevo }}$ equilibration rate constant. The Ce over time were calculated as the convolution of the predicted plasma concentrations over time with the disposition function of the effect site. The convolution was based on a "connect the dots" approach, previously used by Schnider et al. ${ }^{11}$ The $k_{\mathrm{e} 0}$ was estimated by minimizing the area of the hysteresis loop of either EEG index data versus $\mathrm{Ce}_{\text {sevo. }}$ The mathematical approach can be found elsewhere. ${ }^{12}$

The relation between $\mathrm{Ce}_{\text {sevo }}$ and BIS or CSI was modeled using a sigmoidal $E_{\max }$ model:

$$
\text { Effect }=E_{0}+\left(E_{\max }-E_{0}\right) \frac{\mathrm{Ce}_{\text {sevo }}^{\gamma}}{\mathrm{Ce}_{50 \text { sevo }}^{\gamma}+\mathrm{Ce}_{\text {sevo }}^{\gamma},}
$$

where effect is the measured BIS or CSI value, $E_{0}$ is the baseline measurement when no drug is present, $E_{\max }$ is the maximum possible drug effect, $\mathrm{Ce}_{\text {sevo }}$ is the calculated effect-site concentration of sevoflurane, $\mathrm{Ce}_{50 \text { sevo }}$ is the effect-site concentration 
Figure 2. Relationship between the individual measured bispectral index (BIS) and cerebral state index (CSI) values versus the measured sevoflurane end-tidal concentrations. The hysteresis in the relationship is revealed in both plots.
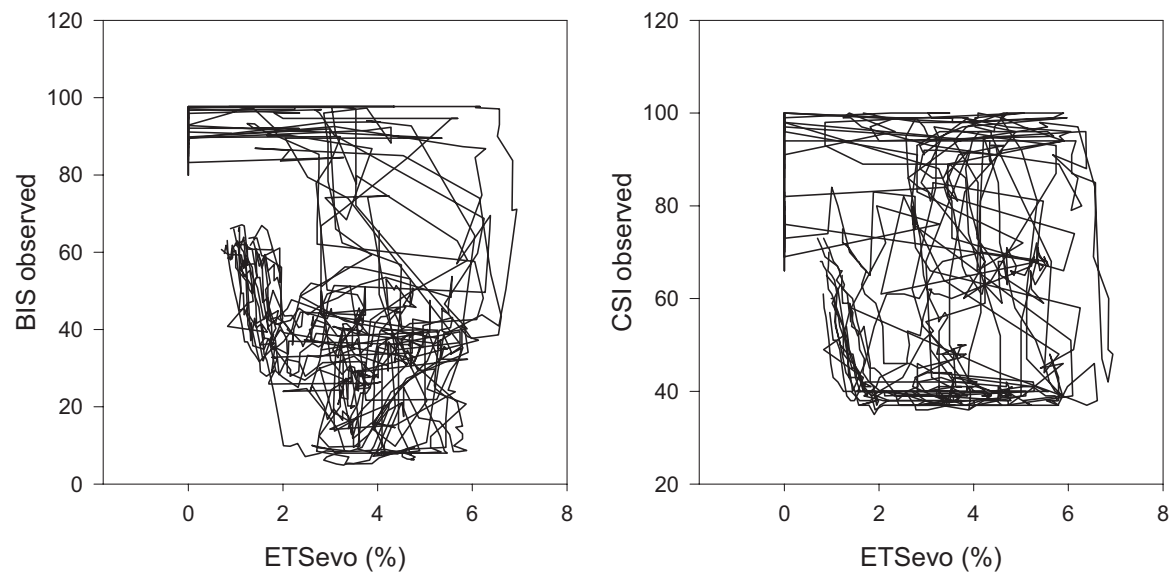

associated with $50 \%$ maximal drug effect, and $\gamma$ is the steepness of the concentration-response relation curve. The model parameters were estimated using NONMEM V (Globomax LLC, Hanover, MD). ${ }^{13}$ Interindividual variability was assumed to have a log-normal distribution:

$$
P_{\mathrm{i}}=P_{\mathrm{tv}} e^{-\eta i}
$$

where $P_{i}$ is the parameter value $\left(K_{\mathrm{e} 0}, E_{0}, E_{\max }, \gamma\right.$, or $\left(e_{50}\right)$ in the $i$ th patient, $P_{\mathrm{tv}}$ is the typical value of the parameter in the population, and $\eta$ is a random variable with a mean of 0 and a variance of $\omega^{2}$. Individual variability is reported as $\omega$, the SD of $\eta$ in the log domain, which is approximately the coefficient of variance in the standard domain. Residual intraindividual variability was modeled using a standard additive error model.

The goodness of the model fit was evaluated. We calculated the population prediction error (PE) between the observed values and post hoc Bayes predicted values for BIS and CSI and the absolute median prediction error (MDAPE) for each patient. ${ }^{14}$ Differences between both indices for PE and MDAPE were tested using a Student's $t$-test.

Normality of data was tested with the KolmogorovSmirnov test. Comparisons between monitors were performed with paired Student's t-test or Wilcoxon's signed rank test. A $P$ value $<0.05$ was considered statistically significant. Statistical analyses were performed using $\mathrm{R}$ (language and environment for statistical computing, freely available from http://www. r-project.org/). Data are mean \pm SD (range) or typical value (coefficient of variation).

\section{RESULTS}

All patients, 7 female and 8 male, age $8.1 \pm 3.6$ (3.6-15.0), weight $35.3 \pm 15.9,(16-65)$, and height $131 \pm 23$ (97-168), completed the study. No conflict in the positioning of the two sensors was observed. Adequate airway management was obtained in all patients without requiring insertion of an oral
Table 1. Parameters Estimated with Each Electroencephalogram Monitor

\begin{tabular}{lll}
\hline & \multicolumn{1}{c}{ CSI } & \multicolumn{1}{c}{ BIS } \\
\hline$E_{0}$ & $84[4](39)$ & $87[1](7)$ \\
$E_{\max }$ & $45[9]$ & $27[17](39)^{*}$ \\
$\mathrm{Ce}_{50}(\%)$ & $2.1[8](68)$ & $2.1[0](16)$ \\
$\gamma$ & $6.9[45]$ & $5.4[14]$ \\
$t_{1 / 2} k_{\mathrm{e} 0}(\min )$ & $2.0[19](14)$ & $1.2[0](53)^{*}$ \\
\hline
\end{tabular}

Results from the population model are presented as parameter estimates, together with the corresponding relative standard error of the estimate [RSE\%]. RSE are calculated as the ratio between the standard error and the estimate of the parameter. Interindividual variability is expressed as coefficient of variation (CV\%).

$\mathrm{BIS}=$ bispectral index; $\mathrm{CSI}=$ cerebral state index.

$* P<0.05$.

airway. Peripheral oxygen saturation was maintained above $95 \%$ throughout the study period in all children.

Measured awake BIS and CSI values were $91.7 \pm$ 4.4 and $89.2 \pm 10.4$, respectively (NS). Awake CSI values ranged from 100 to 63 showing a wider dispersion than BIS (98-80). During the baseline period, the maximum levels of electromyographic (EMG) activity were recorded in both monitors, CSM $(96 \%$ $\pm 10 \%)$ and BIS $(48 \% \pm 3 \%)(P<0.05)$. The signal quality index was $>20 \%$ in both monitors during this period. The minimum BIS and CSI values observed during the study period were $10.8 \pm 5.8$ and $36.9 \pm 1.1$, respectively $(P<0.05)$. No BS activity was recorded by the BIS or CSI monitors throughout the study period.

Figure 1 shows the time course of BIS, CSI, and $C_{\mathrm{ETsevo}}$ for each patient. The hysteresis loop between BIS, CSI, and $C_{\text {ETsevo }}$ is shown in Figure 2. A sigmoid $E_{\max }$ model could be fitted to the data of all patients. The rate of change of sevoflurane's effect expressed as the $t_{1 / 2} k_{\mathrm{e} 0}$ was slower with the CSI [2.0 (14) min] than with BIS [1.2 (53) min] $(P<0.05)$. The parameter values estimated with each monitor are in Table 1. We were unable to estimate the variance for some of the parameters. The residual error for each model (as a measure of the intraindividual variability in the log domain) was 9.45 for BIS and 11.05 for CSI. 

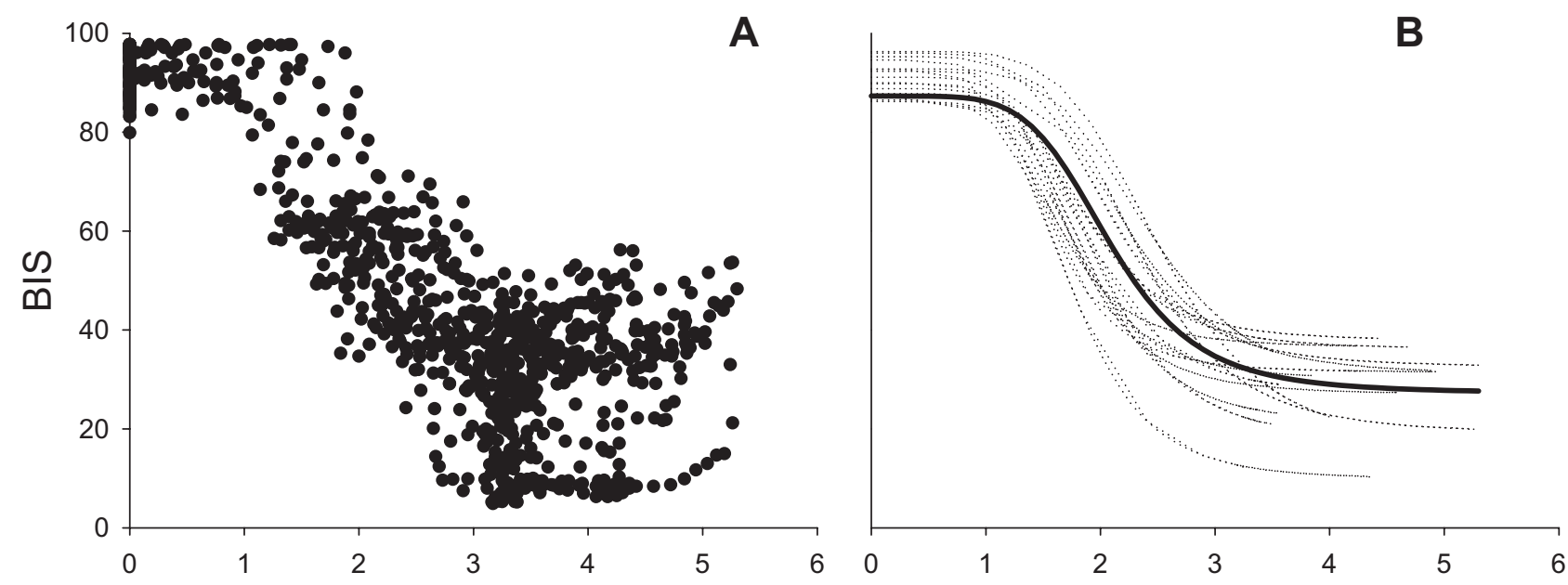

\section{Sevoflurane effect site concentration (\%)}

Figure 3. Observed raw bispectral index (BIS) data of all patients versus sevoflurane effect-site concentration (Ce sevo $)$. (A) Sigmoid $E_{\max }$ model of the BIS versus $\mathrm{Ce}_{\text {sevo }}$ (B) The thin lines represent individual patient fits, whereas the bold line represents the typical curve of the population data. BIS progressively decreased when $\mathrm{Ce}_{\text {sevo }}$ concentrations increased from $0 \%$ to $3 \%$. At higher $\mathrm{Ce}_{\text {sevo }}(3 \%-5 \%)$, BIS tended to stabilize in values lower than 40 .

\section{Observed}

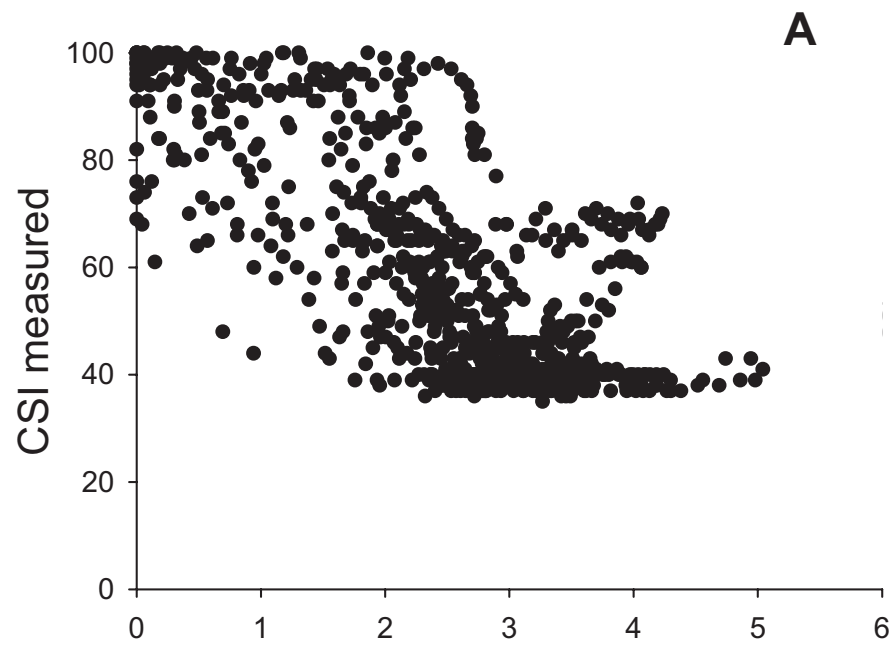

Predicted

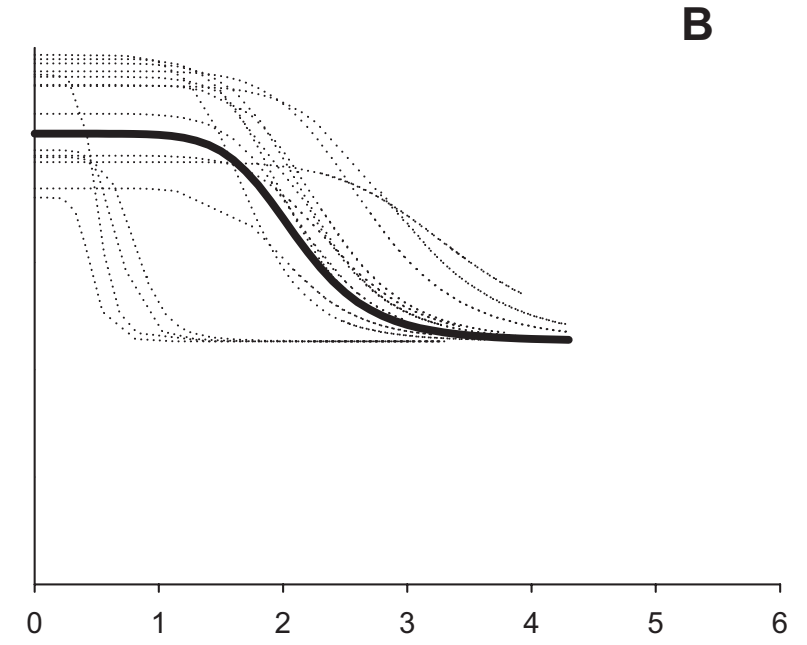

\section{Sevoflurane effect site concentration (\%)}

Figure 4. Observed raw cerebral state index (CSI) data of all patients versus sevoflurane effect site concentration (Ce $\left.e_{\text {sevo }}\right)$. (A) Sigmoid $E_{\max }$ model of the CSI versus $\left(\mathrm{Ce}_{\text {sevo }}\right)$. (B) The thin lines represent individual patient fits, whereas the bold line represents the typical curve of the population data. CSI progressively decreased when $\mathrm{Ce}_{\text {sevo }}$ concentrations increased from $0 \%$ to $3 \%$. At higher $\mathrm{Ce}_{\text {sevo }}(3 \%-5 \%)$ CSI tended to stabilize in values of around 40 .

The relations between the observed and the post hoc Bayesian predicted BIS and CSI versus $\mathrm{Ce}_{\text {sevo }}$ are plotted in Figures 3 and 4. With increasing $\mathrm{Ce}_{\text {sevo, }}$, both BIS and CSI decreased.

The goodness of the model fit was first analyzed by observing the relation between observed and post hoc Bayesian predicted values of BIS and CSI. As observed in Figure 5, a smaller scatter was observed for BIS than for CSI. The population PE was significantly better for BIS $(-0.71 \pm 26.9)$ than for CSI $(-2.95 \pm 178.62)(P<$
0.05). The MDAPE for BIS (12.09 \pm 4.47$)$ and for CSI $(14.10+4.87)$ were similar $(P=0.24)$.

\section{DISCUSSION}

This study quantified and compared the relationship between $C_{\text {ETsevo }}$ and BIS or CSI during sevoflurane anesthesia in children. The major finding of this study is that the parameters of the pharmacokinetic and pharmacodynamic model were entirely dependent on the monitor used to measure sevoflurane's effect. 

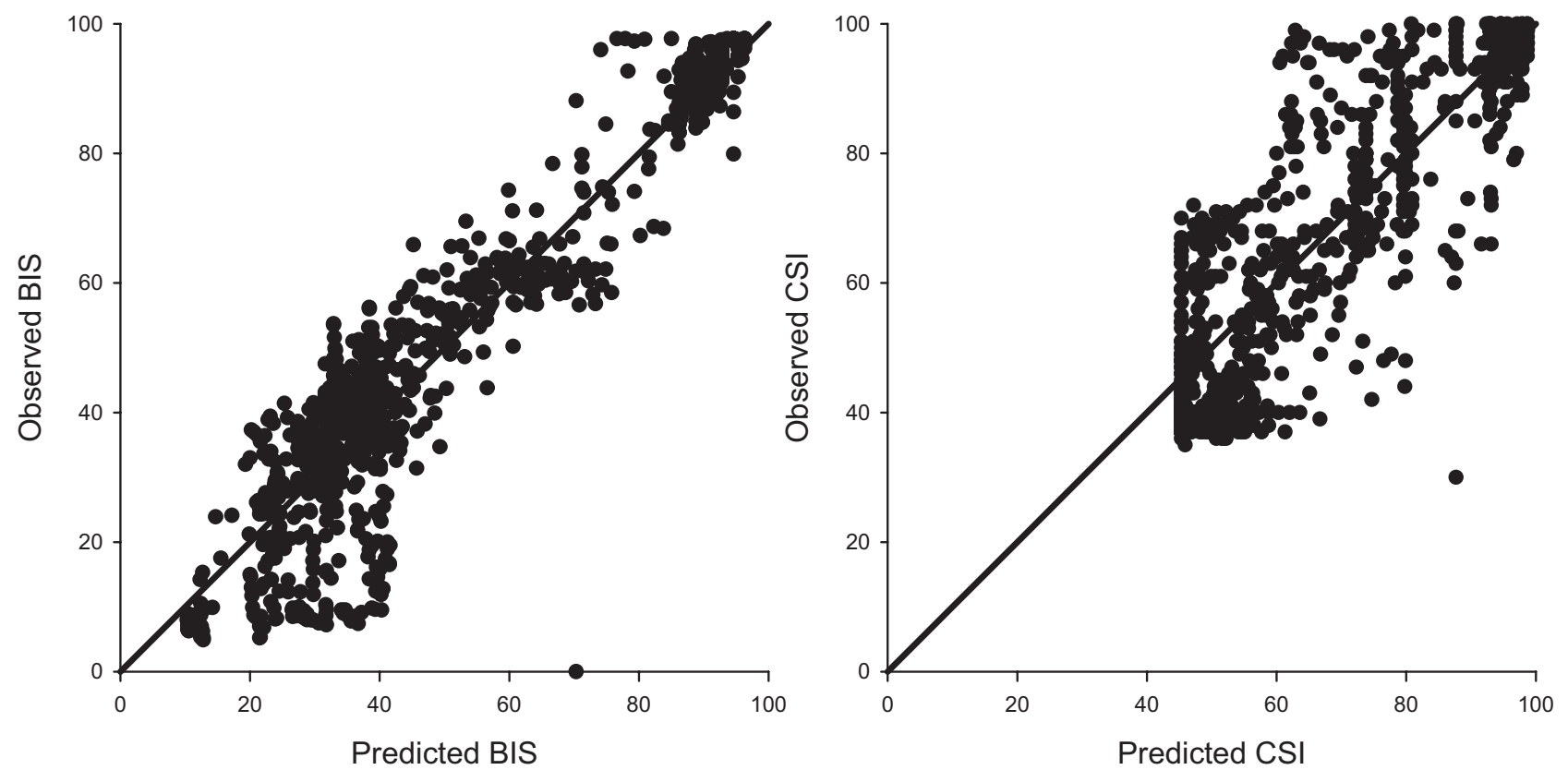

Figure 5. Scatter plot of the observed versus individual predictions (post hoc Bayesian estimates) values of bispectral index (BIS) and cerebral state index (CSI). The solid line represents the identity line. The adequacy of the structural model is corroborated (observed vs individual predictions data lie very close to the identity line).

The $t_{1 / 2} k_{\mathrm{e} 0}$ in this study not only represents sevoflurane's end-tidal to brain equilibration time, but also the time delay of the index used to measure sevoflurane's effect. In a study using simulated EEG signals, Pilge et al. ${ }^{15}$ showed that all currently available EEG indices had different time lags to react to a change in the level of anesthesia. The authors also showed that these delays were not constant, and that they varied depending on the depth of anesthetic level and on whether this level was increasing or decreasing. The response measured by these monitors and the computational delays involved in the calculation of the corresponding EEG indices will influence the $t_{1 / 2} k_{\mathrm{e} 0}$. In the present study, the lower $t_{1 / 2} k_{\mathrm{e} 0}$ estimated with BIS indicated faster on and offset times for the response measured with this monitor compared with the response measured by the CSM. This finding is consistent with Pilge et al.'s results, where time delays of BIS tended to be shorter than CSI delays when intermediate ranges of anesthetic depth were simulated. ${ }^{15}$

The Ce versus effect relationship for sevoflurane was also found to be influenced by the monitor used to measure its hypnotic effect. Although BIS and CSI are both ordinal scales, these variables were treated as continuous data in the model analysis. This assumes that changes in these indices represent a relative change in the magnitude of hypnosis. Both indices showed similar awake values with a wider dispersion observed in the CSI. With this last index, values indicative of sedation were observed in some patients before sevoflurane administration. Both BIS and CSI then progressively decreased during sevoflurane induction (Fig. 1). However, BIS showed a more pronounced and less variable decrease compared with
CSI (Figs. 3 and 4, respectively). At deeper anesthetic levels $\left(\mathrm{Ce}_{\text {sevo }}>3 \%\right)$, both indices tended to stabilize, but BIS reached lower $E_{\max }$ values than CSI, which showed a plateau around 40 . This plateau might be explained because the CSI does not include frequencies below $6 \mathrm{~Hz}$ in its algorithm. ${ }^{6}$ Therefore, $\delta$ waves, typically present during deep anesthesia, are not detected by the CSI, leading to poor correlation with the $\mathrm{Ce}_{\text {sevo }}$ until BS is observed. This is particularly the case in this study, as no BS was observed. It has been shown that the CSI can decrease below 40 if BS is registered but is very unlikely to do so if no BS is observed. $^{6,8}$

EMG activity can contaminate EEG signals and might alter the value of EEG-derived indices. In our study, high levels of EMG activity were recorded during the baseline period and at the beginning of the induction period. The wide range of CSI values observed during baseline and during light anesthesia suggests that this index is highly affected by EMG activity. In addition, there is a new pediatric BIS sensor with four electrodes (not used in the current study) that is supposed to better detect and discard artifacts in the signal, improving the performance of this monitor, especially during light anesthesia.

Since BIS is currently considered a useful tool to guide anesthetic doses in children $>1 \mathrm{yr}^{1}{ }^{1}$ we decided to include a broad age range to increase the general applicability of our results. It can be argued that the age range chosen was too wide and that age changes in EEG might be influencing our results. ${ }^{16}$ However, it has been described that awake BIS values in children between 1 and $15 \mathrm{yr}$ are close to values reported in adult patients and that the BIS 
response during emergence from sevoflurane anesthesia is also relatively similar to that reported in adult studies. ${ }^{17}$

Another limitation of this study is that clinical variables of consciousness were not incorporated in the analysis. However, the relatively long and variable time delays of all currently available EEG monitors ${ }^{15}$ limit the applicability of these variables as markers of imminent loss of consciousness when rapid infusion schemes of anesthetics are used. ${ }^{18}$ We think that to reliably assess clinical end-points and to correlate them with the corresponding EEG index or Ce, slower induction rates or steady-state designs are more adequate.

Advisory systems for sevoflurane administration have been assessed in adult patients showing an improvement in the titration of this drug. ${ }^{19}$ Some future development of an on-line available pharmacodynamic model derived from our results in children might be useful to guide drug administration in this population. However, differences in the measured response by these monitors should be considered.

\section{CONCLUSIONS}

In children, the $t_{1 / 2} k_{\mathrm{e} 0}$ of sevoflurane and the pharmacodynamics of sevoflurane were quantified and the results entirely depended on the monitor used to measure its hypnotic effect. Within the anesthetic depth range studied, the rate of change of sevoflurane's effect was slower with the CSI. To adequately guide sevoflurane administration with these monitors in children, these differences should be considered.

\section{REFERENCES}

1. Davidson AJ. Measuring anesthesia in children using the EEG. Paediatr Anaesth 2006;16:374-87

2. Murat I, Constant I. Bispectral index in pediatrics: fashion or a new tool? Paediatr Anaesth 2005;15:177-80

3. Denman WT, Swanson EL, Rosow D, Ezbicki K, Connors PD, Rosow CE. Pediatric evaluation of the bispectral index (BIS) monitor and correlation of BIS with end-tidal sevoflurane concentration in infants and children. Anesth Analg 2000;90:872-7

4. Disma N, Lauretta D, Palermo F, Sapienza D, Ingelmo PM, Astuto M. Level of sedation evaluation with Cerebral State Index and A-Line Arx in children undergoing diagnostic procedures. Paediatr Anaesth 2007;17:445-51
5. Rampil IJ. A primer for EEG signal processing in anesthesia. Anesthesiology 1998;89:980-1002

6. Jensen EW, Litvan H, Revuelta M, Rodriguez BE, Caminal P, Martinez P, Vereecke H, Struys MM. Cerebral state index during propofol anesthesia: a comparison with the bispectral index and the A-line ARX index. Anesthesiology 2006;105: 28-36

7. Munoz HR, Leon PE, Cortinez L. Evaluation of the simultaneous performance of two monitors of depth of anaesthesia in children. Eur J Anaesthesiol 2007;24(suppl 39):10AP1-7

8. Cortinez L, Delfino A, Fuentes R, Muñoz H. Performance of the cerebral state index during increasing levels of propofol anesthesia: a comparison with the bispectral index. Anesth Analg 2007;104:605-10

9. Sheiner LB, Stanski DR, Vozeh S, Miller RD, Ham J. Simultaneous modeling of pharmacokinetics and pharmacodynamics: application to d-tubocurarine. Clin Pharmacol Ther 1979;25: 358-71

10. Zhong T, Guo QL, Pang YD, Peng LF, Li CL. Comparative evaluation of the cerebral state index and the bispectral index during target-controlled infusion of propofol. Br J Anaesth 2005;95:798-802

11. Schnider TW, Minto CF, Shafer SL, Gambus PL, Andresen C, Goodale DB, Youngs EJ. The influence of age on propofol pharmacodynamics. Anesthesiology 1999;90:1502-16

12. Struys MM, Coppens MJ, De Neve N, Mortier EP, Doufas AG, Van Bocxlaer JF, Shafer SL. Influence of administration rate on propofol plasma-effect site equilibration. Anesthesiology 2007; 107:386-96

13. Beal S, Sheiner L. NONMEM User's Guide. San Francisco: University of California, 1992

14. Varvel JR, Donoho DL, Shafer SL. Measuring the predictive performance of computer-controlled infusion pumps. J Pharmacokinet Biopharm 1992;20:63-94

15. Pilge S, Zanner R, Schneider G, Blum J, Kreuzer M, Kochs EF. Time delay of index calculation: analysis of cerebral state, bispectral, and narcotrend indices. Anesthesiology 2006;104: 488-94

16. Wodey E, Tirel O, Bansard JY, Terrier A, Chanavaz C, Harris R, Ecoffey C, Senhadji L. Impact of age on both BIS values and EEG bispectrum during anaesthesia with sevoflurane in children. Br J Anaesth 2005;94:810-20

17. Davidson AJ, McCann ME, Devavaram P, Auble SA, Sullivan LJ, Gillis JM, Laussen PC. The differences in the bispectral index between infants and children during emergence from anesthesia after circumcision surgery. Anesth Analg 2001;93:326-30

18. Kuizenga K, Wierda JM, Kalkman CJ. Biphasic EEG changes in relation to loss of consciousness during induction with thiopental, propofol, etomidate, midazolam or sevoflurane. Br J Anaesth 2001;86:354-60

19. Kennedy RR, French RA, Gilles S. The effect of a model-based predictive display on the control of end-tidal sevoflurane concentrations during low-flow anesthesia. Anesth Analg 2004;99: 1159-63 